\title{
Peripartum Cardiomyopathy in the Cardiology Department of the CHU Point G
}

\author{
Mariam Sako1*, Massama Konaté2, Boubacar Sonfo³, Samba Sidibé1, Ali Dembélé1, \\ Yves Roland Koumaré1, Nouhoum Diallo', Souleymane Mariko4, Aniessa Kodio5, \\ Bassirima Traoré1, Boureima Dembélé1, Alou Sangaré1, Diarra Ami ${ }^{1}$, \\ Mamadou Diakité1, Souleymane Coulibaly ${ }^{1}$, Ichaka Menta ${ }^{6}$
}

\author{
${ }^{1}$ Hôpital Point G, Bamako, Mali \\ ${ }^{2}$ Hôpital du Mali, Bamako, Mali \\ ${ }^{3}$ Hôpital de Kati, Kati, Mali \\ ${ }^{4}$ Hôpital de Tombouctou, Tombouctou, Mali \\ ${ }^{5}$ Hôpital de Ségou, Ségou, Mali \\ ${ }^{6}$ Hôpital Gabriel Touré, Bamako, Mali \\ Email: *koumareyvesroland@gmail.com
}

How to cite this paper: Sako, M., Konaté, M., Sonfo, B., Sidibé, S., Dembélé, A. Koumaré, Y.R., Diallo, N., Mariko, S., Kodio, A., Traoré, B., Dembélé, B., Sangaré, A., Ami, D., Diakité, M., Coulibaly, S. and Menta, I. (2021) Peripartum Cardiomyopathy in the Cardiology Department of the CHU Point G. World Journal of Cardiovascular Diseases, 11, 603-609. https://doi.org/10.4236/wjcd.2021.1112057

Received: October 21, 2021

Accepted: December 24, 2021

Published: December 27, 2021

Copyright () 2021 by author(s) and Scientific Research Publishing Inc. This work is licensed under the Creative Commons Attribution International License (CC BY 4.0).

http://creativecommons.org/licenses/by/4.0/

\section{(c) (i) Open Access}

\begin{abstract}
Objective: This work aimed to evaluate the epidemiological clinical aspects and evolutionary aspects of peri partum cardiomyopathy (PPCM) in the cardiology department of the CHU Point G. Materials and Methods: This was a descriptive cross-sectional study from 01 January 2019 to 31 December 2019, including all patients admitted for heart failure during this period. Results: The study involved 40 patients out of 1187 admissions, a hospital prevalence of PPCM was $3.36 \%$. The average age was 26 years plus or minus 7 years with extremes of 16 years and 38 years. The age group between 16 and 20 years was the most represented with $32.5 \%$ of cases. Housewives were in the majority with $87.6 \%$; residing in rural areas $62.5 \%$, with a low socio-economic standard of living $32.5 \%$ of cases. Multiparous in our context were dominant $42.5 \%$, followed by pauci pares and primiparous with $32.5 \%$ and $25 \%$ frequency respectively. All our patients, $100 \%$ had their first symptom after childbirth, functional signs were dominated by dyspnea of effort present in $100 \%$ of patients, followed cough $(40 \%)$ and chest pain $(27.5 \%)$. On physical examination there was Tachycardia in $82.5 \%$, Galop B3 (45\%) and auscultatory arrhythmia in 5\%. Signs of pulmonary condensation (82.5\%) and pleural fluid effusion (25\%). Hepatomegaly was present in $72.5 \%$ of patients. It was overall heart failure in $72.5 \%$ of cases. On the electrocardiogram there was sinus tachycardia (75\%) and atrial fibrillation arrhythmia (5\%). On cardiac Doppler ultrasound the left ventricle was dilated with a low systolic ejection fraction in $100 \%$ of patients, the four cavities were dilated in $32.5 \%$, a left in-
\end{abstract}


traventricular thrombus in $7.5 \%$ of cases and a pericardial fluid effusion in $5 \%$ of cases. Biology noted anemia in $22.5 \%$ of patients. Treatment was classic for heart failure. The course was punctuated by complications in $42.5 \%$ of cases, such as thromboembolic disease (22.5\%), ischemic stroke (12.5\%), complete arrhythmia by atrial fibrillation (ACFA 5\%) and cardiogenic shock (2.5\%). Hospital mortality was $7.5 \%$ with $67 \%$ of deaths observed in the 16 22 age group. Conclusion: PPCM is a common sub-Saharan pathology, low socioeconomic status, young age and multiparity were factors dominant in our context.

\section{Keywords}

Cardiomyopathy, Peri Partum, Epidemiology, Clinic, Evolution

\section{Introduction}

Peripartum cardiomyopathy (PPCM), commonly referred to as Meadows' heart disease, is a primary cardiomyopathy responsible for congestive heart failure that occurs in the last month of pregnancy or the first five months of postpartum without further etiology of heart failure. The diagnosis is carried by the presence of cardiographic ultrasound signs attesting to left ventricular dysfunction, with LVEF $<45 \%$ and/or a shortening fraction $<30 \%$ and/or cavitary dilation with a left ventricular tele diastolic diameter $>2.7 \mathrm{~cm} / \mathrm{m}^{2}$ of body surface area with no other obvious cause [1]. PPCM accounts for minus $1 \%$ of pregnancy-related cardiovascular problems in developed countries [2] [3]. Its frequency is higher in sub-Saharan Africa than in regions of the world [2] [4], it accounted for $9.9 \%$ of cardiovascular diseases in 2016 according to a study conducted in the hospital environment of Parakou [5]. In Mali, it accounted for $11.4 \%$ of heart failure in cardiology at CHU G Touré (2000-2001) [6] and 22.3\% of dilated cardiomyopathies in cardiology at CHU Point G in 2013 [7]. A polyfactorial origin has been considered by several authors [4] [8]. The evolution of this condition can be towards complete healing that can allow another subsequent conception [7] [9] [10]. This pathology is given its high frequency and morbidity, the absence of known etiology and the multiplicity of favoring factors make the interest of this work which aimed to study the epidemiological, clinical, and evolutionary aspects of peri partum cardiomyopathy in the cardiology department of the CHU Point G.

\section{Materials and Methods}

This was a prospective cross-sectional study spread from 01 January 2019 to 31 December 2019.

The inclusion criteria were all patients hospitalized in the ward for heart failure syndrome installed in the last month of pregnancy or five months after delivery with cardiac ultrasound signs. 
The following were excluded:

- Parturient with subsequent underlying heart disease

- Heart failure outside of pregnancy

- Patients without cardiac ultrasound

The diagnosis was made by cardiac ultrasound highlighting a left ventricular dysfunction with an LVEF less than $45 \%$ and or a shortening fraction of less than $30 \%$, and/or left ventricular cavitary dilation with a tele diastolic diameter (DVTD) to greater than $2.7 \mathrm{~cm} / \mathrm{m}^{2}$ of body surface without any other explanatory cause.

\section{Data collection}

Patients were recruited from hospitalization records with socio-demographic, clinical, paraclinical (biological, electrical, ultrasound), therapeutic and evolutionary parameters. The analysis and data entry were done by Microsoft Word 2010, IBM SPSS version 21 software. The statistical tests were the Khi 2 and the Fischer test with the statistical probability threshold at $5 \%$. The consent of all patients was sought.

\section{Results}

During the study period on 1187 patients admitted, 40 were admitted for CMPP, a hospital prevalence of $3.36 \%$. The average age in the series was 26 years plus or minus 7 years with extremes of 16 years and 38 years. The modal class was 16 to 22 years with $32.5 \%$ of cases (Table 1 ). Housewives were in the majority with $87.6 \%$; residing in rural areas $62.5 \%$ (Table 2), and an average socio-economic standard of living in $65 \%$ of cases and low in $32.5 \%$ of cases (low monthly income below Mali's SMIG: 40,000 FCFA, 1 euro $=655$ FCFA). Multiparous people were in the majority $42.5 \%$ of cases, followed by pauci pares and primiparous people with $32.5 \%$ and $25 \%$ of cases respectively (Table 3 ). All our patients, $100 \%$ had their first symptom after childbirth, functional signs were dominated by exercise dyspnea of effort present in $100 \%$ of patients, followed cough (40\%) and chest pain (27.5\%). On physical examination, there was Tachycardia in $82.5 \%$, Galop B3 (45\%) and auscultatory arrhythmia in 5\%. Signs of pulmonary condensation (82.5\%) and pleural fluid effusion (25\%). Hepatomegaly was present in $72.5 \%$ of patients. It was overall heart failure in $72.5 \%$ of cases. On the electrocardiogram there was sinus tachycardia (75\%) and atrial fibrillation arrhythmia (5\%). On cardiac Doppler ultrasound the left ventricle was dilated with a low systolic ejection fraction in $100 \%$ of patients, the four cavities were dilated in $32.5 \%$, a left intraventricular thrombus in $7.5 \%$ of cases and a pericardial fluid effusion in $5 \%$ of cases. Biology noted anemia in $22.5 \%$ of patients. Treatment was classic for heart failure, the handle diuretic (100\%), ace inhibitor (100\%), spironolactone (60\%), digitalis (5\%), B blocker (80\%) and dobutamine (2.5\%). Complications were noted in $42.5 \%$ of cases, such as thromboembolic disease (22.5\%), ischemic stroke (12.5\%), complete arrhythmia by ACFA atrial fibrillation (5\%) and cardiogenic shock (2.5\%) (Table 4). The average hospital stay was 
Table 1. Distribution of patients by age group.

\begin{tabular}{ccc}
\hline Age group (years) & Staff & Percentage \\
\hline $16-22$ & 13 & 32.5 \\
$23-28$ & 9 & 22.5 \\
$29-34$ & 11 & 27.5 \\
$35-40$ & 7 & 17.5 \\
Total & 40 & 100 \\
\hline
\end{tabular}

Table 2. Distribution of patients by occupation.

\begin{tabular}{ccc}
\hline Profession & Staff & Percentage \\
\hline Housewife & 35 & 87.5 \\
Merchant & 03 & 7.5 \\
Official & 01 & 2.5 \\
student & 01 & 2.5 \\
Total & 40 & 100 \\
\hline
\end{tabular}

Table 3. Distribution of patients by obstetric ATCD.

\begin{tabular}{ccc}
\hline Obstetric history & Staff & Pourcentage \\
\hline Multiparous & 17 & 42.5 \\
Pauci pare & 13 & 32.5 \\
Primipare & 10 & 25 \\
Total & 40 & 100.0 \\
\hline
\end{tabular}

Table 4. Distribution of patients by hospital evolution.

\begin{tabular}{ccc}
\hline Evolution & Staff & Pourcentage \\
\hline Complication & & \\
Pulmonary embolism & 9 & 22.5 \\
Ischemic stroke & 5 & 12.5 \\
ACFA & 2 & 5.0 \\
Cardiogenic shock & 1 & 2.5 \\
Favorable & 20 & 50 \\
Death & 03 & 7.5 \\
Total & 40 & 100
\end{tabular}

15 days plus or minus 6 days. Hospital mortality was $7.5 \%$ and $67 \%$ of deaths were observed in the $16-22$ age group.

\section{Discussions and Comments}

Limitations of the study include: 
The high cost of hospitalization in the cardiology department.

Insufficient collaboration with the maternity ward during recruitment.

And the small sample size.

During the study period, we collected 40 patients meeting the inclusion criteria in a population of 1187 patients, a hospital frequency of 3.36\%. This denotes the high index of this condition in our country.

Our prevalence was lower than $11.4 \%$ of COULIBALY A [6] in Mali and $12.8 \%$ of ADJAGBA in Benin [11]. This could be explained by the difference in the size of our samples and the increase in the number of cardiovascular disease treatment centers in Bamako. The extreme ages were 16 and 38 with an average of $26 \pm 7$. This is close to the average age found by DIARRA A [12] in Mali and FERRIERE [13] in France which was 29 years old. Pio $\mathrm{M}$ et al. [14] in Togo found an average age of 31 years. These results do not allow us to define a preferred age of peri partum heart disease. The age group from 16 to 22 years was the most represented with $32.5 \%$ of cases, This could be explained by the phenomenon of early marriage. In our study, the affected women met the following profile: Black African women, living in rural areas, with a low income, respectively $100 \%, 62.5 \%, 65 \%$ of cases. This is consistent with the literature [5] [15]. The majority of patients were housewives (87.5\%); this could explain the high frequency of physical work in these patients that can promote the occurrence of this pathology [7]. Multiparity was dominant $42.5 \%$ of cases, same found in DEMAKIS [16] in the United States $71 \%$ of cases. All patients had shown the first signs of $\mathrm{CI}$ in the postpartum period, $100 \%$ with extremes ranging from day 7 to month 5. This figure is higher than the $87 \%$ of DIARRA A [12] in Mali and the $78 \%$ of LAMPER (France) [17]. These results testify to the frequency of this condition in the postpartum. Complications were dominated by thromboembolic events such as pulmonary embolism and AVCI with $22.5 \%$ and $12.5 \%$ of cases respectively, ACFA was present in 5\% of cases and cardiogenic shock $2.5 \%$ of cases; testifying to the significant impairment of the contractile function of the myocardium and the delay in the diagnosis of the disease. The course was favorable without complications in half of the patients $50 \%$ of the cases; hospital mortality was $7.5 \%$ of cases $(\mathrm{n}=3)$, compared to $1.43 \%$ in COULIBALY B [18] in Mali and $15.3 \%$ of cases in FET JD in Haiti [19]. This could be explained by the fact that most of the patients were seen in the late stage of their disease. The factors of poor prognosis in our study were: young age with no statistically significant link and multiparity. Unlike the literature, it is high age and multiparity that are the factors of poor prognosis. This could be explained by the fact that three quarters of our patients were under the age of 34 . The majority of deceased patients were in the 16 - 22 age group. COULIBALY B [18] in Mali had found high mortality in the age group from 25 to 34 years. However, it should be noted that the low numbers did not make the statistical test performed powerful, which did not make it possible to verify any correlation between the prognostic variables. Two out of three patients who died had a low socioeconomic status of 
$67 \%$, compared to $100 \%$ of cases of death in patients with low socioeconomic status in the COULIBALY B study [6], performing physical labor during pregnancy. However, there is no statistically significant link between low socioeconomic status, physical labour during pregnancy and death $(\mathrm{P}=0.30)$.

\section{Conclusion}

CMPP is a common sub-Saharan pathology, low socioeconomic status, young age and multiparity were dominant factors in our context.

\section{Recommendations}

The occurrence of a CMPP is a real social drama that can force to intervene on the maternity of a woman. The absence of a formal etiology means that our recommendations arise in terms of awareness and research.

Sensitization:

At the level of patients and their parents:

- Consult as much as possible in health facilities.

- Regularly follow the prenatal consultation.

- Use contraceptive methods or consider scheduled pregnancies. At the level of socio-health personnel:

- Refer to specialists any woman with postpartum IC symptoms;

- Organize information-education-communication campaigns for populations

- Strengthen the multidisciplinary relationship.

At the level of policy makers:

- Improvement of the socio-economic conditions of pregnant women.

- Strengthen accessibility to care.

Research:

- We consider it necessary to continue research at the national level and in order to identify the characteristics of this disease.

\section{Conflicts of Interest}

The authors declare no conflicts of interest regarding the publication of this paper.

\section{References}

[1] Pearson, G.D., Veille, J.C. and Rahimtoola, S. (2000) Peripartum Cardiomyopathy. National Heart, Lung, and Blood Institute and Office of Rare Diseases (National Institute of Health). Workshop Recommendations and Review. Journal of the American Medical Association, 283, 1183-1188. https://doi.org/10.1001/jama.283.9.1183

[2] Bahloul, M., Ahmed, M.N. and Laaroussi, L. (2009) Myocardiopathie du péri partum: Incidence, physiopathologie, manifestations cliniques prise en charge et pronostic. Annales Françaises d' Anesthésie et de Réanimation, 28, 44-60. https://doi.org/10.1016/j.annfar.2008.11.001

[3] Letaïfa, D.B., Slama, A. and Khemakhem, K. (1999) Cardiomyopathie du péri partum série des cas cliniques. Annales Françaises d Anesthésie et de Réanimation, 
18, 677-682. https://doi.org/10.1016/S0750-7658(99)80156-7

[4] Ford, L., Abdullahi, A. and Anjorin, F.I. (1998) The Outcome of Peripartum Cardiac Failure in Zaria, Nigeria. Quarterly Journal of Medicine, 91, 93-103. https://doi.org/10.1093/qjmed/91.2.93

[5] Cénac, A., Touré, K. and Diarra, M.B. (2004) Sélénium plasmatique cardiomyopathie du péri partum à Bamako. Medecine Tropicale, 64, 151-154.

[6] Coulibaly, A. (2001) La cardiomyopathie dilatée du péri partum à propos de 49 cas. Thèse, Med, Bamako, No. 47.

[7] Diallo, S. (2013) Prise en charge de la CMPP dans le service de cardiologie du CHU du point G: A propos de 49 cas. Thèse, Med, Bamako, No. 37.

[8] Sliwa, K., Fett, J. and Elkayam, U. (2006) Peripartum Cardiomyopathy. The Lancet, 368, 687-693. https://doi.org/10.1016/S0140-6736(06)69253-2

[9] Baursache, J., Konig, T. and Vander Meer, P. (2019) Physiopathology, Diagnosis and Management of Peripartum Cardiomyopathy. European Journal of Heart Failure, 21, 827-843. https://doi.org/10.1002/ejhf.1493

[10] Karaye, K.M., Ishaq, N.A. and S'aidu, H. (2020) Incidence, Clinique, and Risk Factors of Peripartum Cardiomyopathy in Nigeria. ESC Heart Failure, 7, 236-244. https://doi.org/10.1002/ehf2.12562

[11] Adjagba (2016) Cardiomyopathie du péri partum au service de cardiologie du CNHU-HKM. Thèse, Med, Cotonou (Bénin), No. 152.

[12] Diarra, A. (1983) La myocardiopathie du post-partum. (Syndrome de Meadows). Thèse, Med, Bamako, No. 12.

[13] Ferrier, M., Sacrez, A. and Bouhour, J.B. (1990) La myocardiopathie du péri partum: Aspects actuels. Etude multicentrique: 11 observations. Archives des Maladies du Coeur et des Vaisseaux, 83, 1563-1569.

[14] Pio, M. (2014) Particularités de la cardiomyopathie du péri partum en Afrique: Le cas du Togo sur une étude prospective de 41 cas au Centre Hospitalier et Universitaire Sylvanus Olympio de Lomé. The Pan African Medical Journal, 17, 245. https://doi.org/10.11604/pamj.2014.17.245.3058

[15] Cenac, A., Gaultier, Y., Soumana, I., Toure, I.A. and Develoux, M. (1988) La myocardiopathie post-partum. Evaluation de la réponse clinique et échographique au traitement. 30 cas observés en région soudano sahélienne. La Presse Médicale, 17, 940-944.

[16] Demakis, J.C., Shaubudin, H. and Rahimtoola, S.H. (1971) Peripartum Cardiomyopathy. Circulation, 44, 964-968. https://doi.org/10.1161/01.CIR.44.5.964

[17] Lampert, M.B. and Lang, R.M. (1995) Peripartum Cardiomyopathy. American Heart Journal, 130, 860-870. https://doi.org/10.1016/0002-8703(95)90089-6

[18] Coulibaly, B. (2017) Cardiomyopathie du péri partum dans le service de cardiologie de l'HNF de Ségou: A propos de 70 cas. Thèse, Med, Bamako, No. 65.

[19] Fett, J.D., Christie, L.G., Carraway, R.D. and Murphy, J.G. (2005) Five-Year Prospective Study of the Incidence and Prognosis of Peripartum Cardiomyopathy at a Single Institution. Mayo Clinic Proceedings, 80, 1602-1606.

https://doi.org/10.4065/80.12.1602 